\title{
Study on Influence of Diversified Parameters of Vehicle and Track on Wheel Hollow Wear
}

\author{
Yongjie Lu $\mathbb{D}^{\mathbb{D}},{ }^{1}$ Zongyu Gao, ${ }^{2}$ and Jianxi Wang $\mathbb{D}^{2,3}$ \\ ${ }^{1}$ School of Mechanical Engineering, Shijiazhuang Tiedao University, Shijiazhuang 050043, China \\ ${ }^{2}$ Key Laboratory of Road and Railway Engineering Safety Control of Ministry of Education, Shijiazhuang Tiedao University, \\ Shijiazhuang 050043, China \\ ${ }^{3}$ School of Civil Engineering, Shijiazhuang Tiedao University, Shijiazhuang 050043, China
}

Correspondence should be addressed to Yongjie Lu; lu-yongjie@163.com

Received 19 March 2018; Revised 26 May 2018; Accepted 7 June 2018; Published 9 July 2018

Academic Editor: Giosuè Boscato

Copyright (c) 2018 Yongjie Lu et al. This is an open access article distributed under the Creative Commons Attribution License, which permits unrestricted use, distribution, and reproduction in any medium, provided the original work is properly cited.

\begin{abstract}
Wheel hollow wear of high-speed train is one of the main damage types for the wheel. By optimizing the vehicle and track parameters and matching the wheel-rail profile, the hollow wear of wheel can be reduced. In order to study the sensitivity of vehicle and track parameters to the wheel hollow wear, the sensitivity of suspension parameters and the track parameters of the CRH2Ctype highspeed train wheel on the hollow wear of the wheel was studied by the parameter sensitivity analysis method. The concept of the cumulative wear power dissipation was put forward. The distribution characteristics of the wheel hollow wear under the different wheel/rail treads matching were forecasted. The results show that the damping of antihunting motion damper of the vehicle is the most sensitive to the maximum cumulative wear power dissipation of the wheel, followed by the longitudinal stiffness of tumbler journal box node, lateral stiffness of air-spring suspension, vertical damping of primary suspension, vertical stiffness of track, and vertical damping of track. According to the analysis from the combination of sensitive parameters, the cumulative wear power dissipation is unevenly distributed in the lateral direction of the wheel tread and has the obvious peak area, which is basically the same as the actual wear distribution location in the field. The matching of the LMA wheel tread and the CN60N rail tread is a good choice to slow down the hollow wear and reduce the wheel wear rate. And the wheel reprofiling should be timely carried out, otherwise the wear rate would increase and the hollow wear would become more serious.
\end{abstract}

\section{Introduction}

High-speed train has features such as high speed, safety, comfort, energy conservation, and environment protection which improves the people's travel quality. To ensure highquality running of high-speed train, a friendly wheel-rail relationship is very important. Wheel and rail produce the wear in the process of repeated rolling contact, and the recent field investigation found that tread-hollow wear of high-speed train wheel was very serious [1-3]. The hollow wear of wheel tread severely deteriorated the wheel-rail contact geometry, resulting in an increased dynamic response between the wheel and the rail, which greatly affected the traveling stability, safety, passenger comfort, and service life of the components of the vehicle-track system. A lot of researchers at home and abroad have studied the hazards of the wheel hollow wear, trying to provide a reliable basis for the development of hollow wear control standards and wheel reprofiling. Robert Frohling studied the influence of the wheel hollow wear of the goods train on the curve passing ability and the rail damage. It was pointed out that the rolling contact fatigue damage of the wheel was aggravated by the wheel hollow wear [4]. Sawley [5-7] studied the influence of wheel hollow wear on the wheel-rail contact relationship, stability, wheel-rail lateral force, and energy consumption and analyzed the relationship between left-right wheel diameter difference and vehicle instability due to hollow wear. And the hollow wear was taken as the main parameters to develop a tread reprofiling criteria for goods train of North America [8]. Li Hengli et al. established a multibody dynamic model of vehicle with hollow wear wheel and studied the influence of hollow wear on the vehicle safety [9]. Mace studied the 
eversion of the rail caused by the tread-hollow wear of the wheel $[10,11]$. Tavakkoli established a multibody dynamic model of the vehicle and analyzed the influence of the false wheel flange and the wheel diameter difference caused by hollow wear on the ride stability [12]. Alizadeh Kaklar et al. established a nonlinear mathematical model of a highspeed railway vehicle with 21 degrees of freedom for dynamic analysis of a wagon equipped by the hollow worn wheels on a tangent track. The results showed that both rolling radius difference and false flange hollowing reduced the critical speed of hunting, the influence of rolling radius difference in reduction of the critical speed of hunting is more than that of false flange hollowing, and the influence of false flange hollowing in increase of lateral oscillation amplitude of the wheel set is more than that of rolling radius difference [13]. Woolley carried out a statistical analysis of the hollow wear of the P8 wheel and studied the wheel reprofiling criteria [14]. Li Xiaolong studied the influence of tread downward wear on dynamic performance of the subway vehicle [15]. Huang Zhaowei analyzed the adverse effects of hollow wear and different eccentric wear forms of the wheel on the vehicle dynamic [1], and Sun Yu et al. established a vehicle-track coupling dynamic model in order to study the dynamic behavior of the vehicle with tread worn wheel. Results showed that, compared with the dynamic response of the vehicle without worn wheel, the wheel-rail forces were slightly affected by the tread-hollow-worn wheel, the effect on the wheel-rail lateral force was more significant than that on the wheel-rail vertical force. Both the wheel-rail vertical force and the wheel-rail lateral force were increased to a certain extent at the high frequencies [16]. The hollow tread wheel will not only affect the stability of the vehicle but also affect the safety of the vehicle and even cause derailment. The derailment investigators examined the height difference between the switch point and stock rail as well as the wheel profiles of the derailed cars before determining the cause to be a tread-hollow wheel that contacted the gauge side of the stock rail at a derailment of a loaded coal train at the switch point-to-stock rail transition, trailing point move [17].

Many researchers have discussed the causes of wheel hollow wear. Jin Xuesong et al. carried out the detailed analysis and summary of the transverse wear of high-speed wheel/rail of China (the hollow wear on wheel tread and the wheel flange wear), including its characteristics, the formation mechanism, its effect on high-speed train dynamic behavior, and the measures against such wear pattern. When the hollow wear is in a certain depth range, wheel set hunting occurs and the comfort of vehicle drops [18]. The paper proposed seven measures to suppress or slow down the hollow wear of wheel. Yoshika Akihiro investigated wear patterns of 2794 wheels and speculated that the hollow abrasion was due to the use of sintered brake shoes with large wheel wear or the frequent use of tread brakes [19]; Satto Kenji studied the effect of moderately (or slightly) treadhollow wear of the wheel on the motion characteristics of the vehicle [20]; Sun Xiaojie analyzed the tread wear law from the statistical point of view and concluded that, with the increase in running mileage, the hollow downward wear appeared around 70mm [21]; Li Xia analyzed the causes of abnormal tread wear of subway wheel, and the factors such as excessive brake shoe pressure, uneven pressure, large sloshing of brake shoe, and frequent braking easily led to the double groove wear of the inside of the rolling circle and the outside of the tread [22]; Qing Feng studied the law of influence of tread braking mode and heat load on the tread-hollow wear of wheel and discussed the causes of tread groove wear and hollow wear of subway vehicle [23]; Huang Caihong studied the influence of system parameters on the wheel tread-hollow wear of high-speed train [24].

Wheel hollow wear is an inevitable trend in the wheel-rail wear [18], but how to better characterize the hollow wear and how to slow down the hollow wear are an urgent problem to be solved. Karttunen proposed a multiparameter quantitative characterization method for the hollow wear wheel, analyzed the relationship between these parameters and wheel wear and fatigue, and proved the validity of these parameters in describing the hollow wear wheel [25]. Cui Dabin tracked the wear of high-speed train wheel and found that the hollow wear was the main form of wheel wear and designed a new wheel tread to reduce the wheel hollow wear [26].

When the high-speed train is in service on different railway lines, the railway lines of different zones have different track structure parameters, and the decay of the performance of the train vibration-damping system leads to the differentiation of stiffness of the running parts and damping characteristic parameters. Therefore, the parameters of highspeed train-track system have the feature of being diverse and random. In addition, the wheel wear is a dynamical process of wear accumulation, in which the rail profile and wheel tread change at all times. Therefore, it is necessary to study the mechanism of wheel hollow wear from the view of multiparameter and cumulative wear of the wheelrail system. At the same time, it is necessary to study the effect of vehicle suspension parameters on the hollow wear of the wheel in both the optimization of the wheel/rail profile matching and the antijamming performance design of the vehicle structure in suppressing the hollow wear of wheel [18]. Suspension characteristics can play a significant role in rolling contact fatigue (RCF) and wear, corrugation, and noise [27]. In this paper, the parametric model of high-speed traintrack system was established, the wear power dissipation was used to calculate the wear, the sensitivity of vehicle and track parameters to the wear power dissipation of the wheel was analyzed, and the wheel hollow wear condition under the sensitivity parameters was studied, and the hollow wear condition of the wheel under the different wear states was studied. From the perspective of wheel-rail matching, the distributions of wheel-rail contact points on different wheelrail treads are not the same, and the dynamic behaviors are also different. The conditions of wheel-rail wear and fatigue damage are also different. So, research on wheel-rail profile optimization design can achieve the purpose of reducing wheel-rail dynamic forces and improving wheel-rail contact status by use of the vehicle system dynamic theory [28, 29]. Scholars at home and abroad have studied the reduction of wear by optimizing the wheel tread [28-31]. Vibration characteristics of bogie, car body, or trains are decided by the coordination between stiffness/damping parameters of 


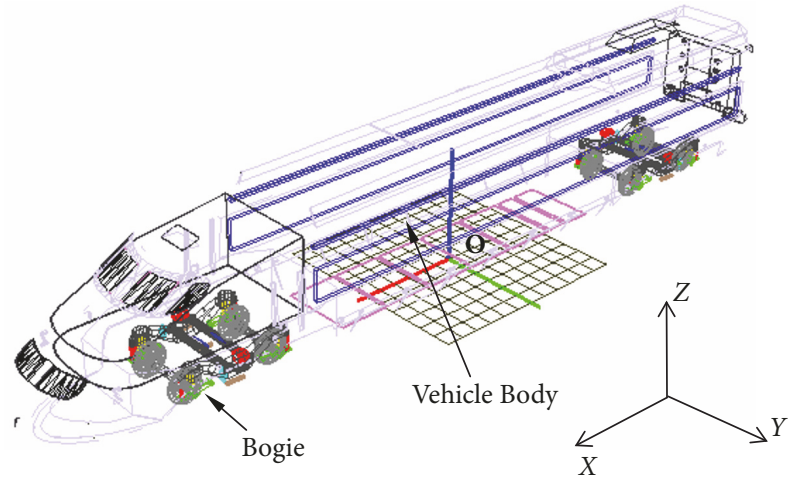

(a) Multibody dynamic model of vehicle

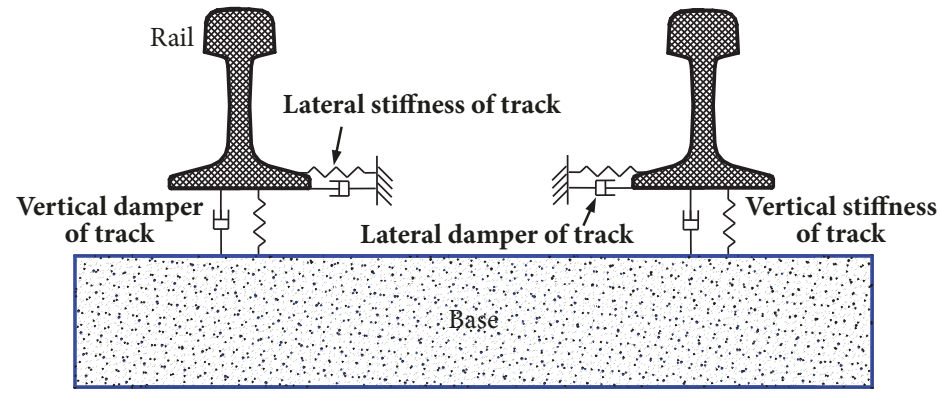

(b) Rail system model

FIGURE 1: Multibody dynamic model of vehicle-track system.

suspension system and structural properties [27]. From the perspective of low dynamic interactions, reducing the wheelrail force can reduce wear. Therefore, the effect of vehicletrack parameters on hollow wear of wheel is analyzed to mitigate the wheel's hollow wear.

\section{Vehicle-Track Dynamic Model and Wheel Wear Model}

2.1. Vehicle-Track Parametric Dynamic Model. According to the multibody dynamic theory, a dynamic model of vehicletrack multibody system was established by the program package "Universal Mechanism," shown in Figure 1. The vehicle model is a CRH2C high-speed train, which consists of a body, two frames, four wheel sets, and eight axle boxes. Wheel sets and frames and frames and body are, respectively, connected through primary steel spring and air spring. In addition to elastic, damping external components in the system, the body, frame, and wheel set were considered as rigid body. A rigid body adopts six degrees of freedom and displaces along the lines of the three coordinate axes and around the rotation of the three coordinate axes, corresponding to six kinds of basic vibration forms such as stretching, traversing, floating, shaking, rolling, and nodding. In the rail system, the rail was treated as a Timoshenko beam. The connection between the beam and the lower foundation was simplified in the vertical direction as a parallel linear spring damper and simplified in the lateral direction as a parallel linear spring damper. In this paper, the coordinate system was established with the projection point of the center of the vehicle body in the track plane as the origin, the vehicle moving direction as the $X$ axis, the vertical track pointing to the left side as the $Y$ axis, and the vertical track plane upward as the $Z$ axis.

The wheel tread adopts LMA wear type tread, and the rail adopts China's $60 \mathrm{~kg} / \mathrm{m}$ CN60 type rail, with track gauge of $1435 \mathrm{~mm}$ and rail cant of $1 / 40$, Chinese high-speed railway ballastless track spectrum [32] is adopted, the proportions of running railway line shapes and various railway line shapes are set according to the proportions of straight line, easement curve and circular curve of a high-speed railway lines, the curve is classified at $300 \sim 350 \mathrm{~km} / \mathrm{h}$ travel speed according to the different superelevations and curve radii, finally the proportions of the straight line, circular curve, and easement curve in the railway line shapes of simulation lines are 39\%, $17 \%$, and $44 \%$, respectively, and the specific railway line parameters are shown in Table 1.

2.2. Calculation Model of Wear Power Dissipation of the Wheel. Based on the wheel/rail wear tests, the wheel-rail wear volume (velocity) is proportional to the creep work on the contact surface between the wheel and rail [33]. When the creep between the wheel and rail reaches saturation, the creep state turns into the sliding state, and the creep rate is the relative sliding distance; creep force becomes changed into friction force, creep work was the friction work, and friction work per unit time is the wear power dissipation. In this paper, the wear power dissipation is used to predict the size of wear volume (velocity) $[34,35]$. The wear power dissipation is

$$
M=F_{x} v_{x}+F_{y} v_{y}
$$


TABLE 1: Linear distribution and line parameters of a high speed railway.

\begin{tabular}{ccccccc}
\hline No Straight line length $(\mathrm{m})$ & Curve length $(\mathrm{m})$ & Direction ${ }^{*}$ & Circular curve radius $(\mathrm{m})$ & $\begin{array}{c}\text { Easement curve length(m) } \\
\text { Cuperelevation } \\
(\mathrm{mm})\end{array}$ \\
\hline 1 & 2000 & 2400 & Right & 7000 & 670 & 170 \\
2 & 2000 & 2400 & Left & 7000 & 590 & 175 \\
3 & 2000 & 2900 & Left & 8000 & 590 & 530 \\
4 & 2000 & 3700 & Right & 9000 & 370 & 140 \\
5 & 2000 & 2400 & Left & 12000 & 35 & 95 \\
\hline
\end{tabular}

* Note: for direction, according to the train driving direction, the curve is divided into left or right turn.

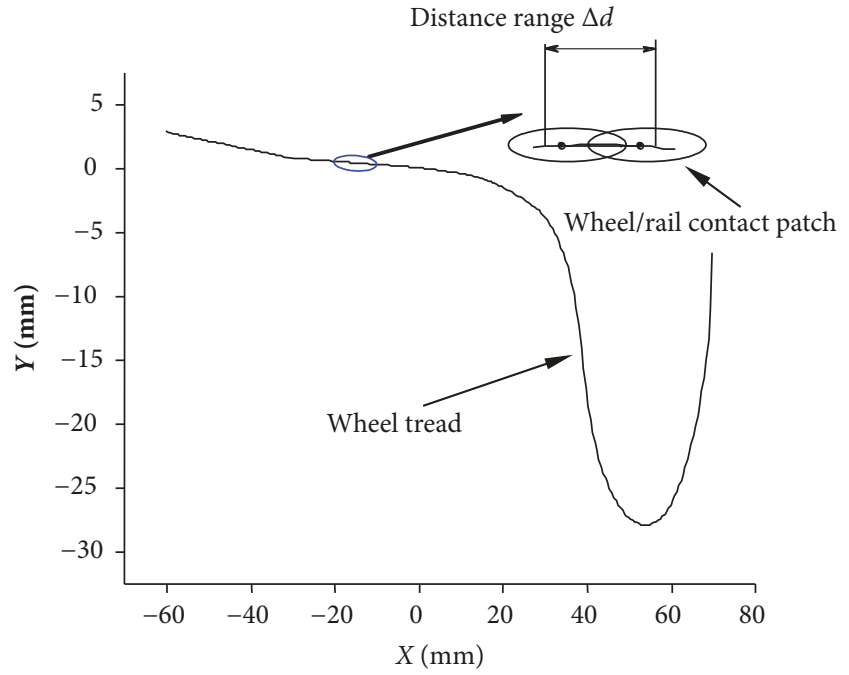

FIGURE 2: Calculation model of cumulative wear power dissipation for wheel tread.

wherein $v_{x}$ and $v_{y}$ are vertical creep rate and horizontal creep rate, respectively, and $F_{x}$ and $F_{y}$ are the longitudinal and lateral creep forces at the contact point of wheel and rail.

The wheel hollow wear is not formed by one-time wear and is a cumulative result of wear. The train travels along the route, and the wheel-rail contact positions change all the time. At the same time, in order to facilitate the analysis of the effect of track and vehicle parameters on wheel hollow wear, more attention should be paid to indicators which the dynamic generated, and the impact of the introduction of non-dynamically generated indicators (such as material parameters) should be reduced on the study. In this way, a new parameter is required. This parameter must not only represent the amount of wear but also represent the wheel-rail contact position. The wear power dissipation is a characterization index of the wear of certain contact time of the wheel. It could not characterize the cumulative wear condition and could not characterize the wear distribution. In order to analyze the wheel hollow wear, this paper introduced the concept of cumulative wear power dissipation. The cumulative wear power dissipation was the accumulated value of the wear power dissipation in the range of $\Delta d$ in the center of all the contact spots in the lateral distribution of the wheel tread. The calculation model is as shown in Figure 2.
In order to analyze the wheel wear more accurately, we took $\Delta d=1 \mathrm{~mm}$ and $\Delta d=x_{i}-x_{i-1}(i=1,2 \ldots, N)(N$ is the number of wheel tread discrete points) and $x_{i}$ was the wheel lateral coordinate and the calculation formula of the cumulative wear power dissipation is as shown in

$$
\operatorname{MWear}\left(x_{i}\right)=\sum_{i=1}^{N} \sum_{j=1}^{L} M_{i j}
$$

wherein $M W e a r\left(x_{i}\right)$ is the cumulative wear power dissipation at step $L$ of $x_{i}$ position; $M_{i j}$ is the cumulative wear power dissipation at step $L$ of $x_{i}$ position; and $L$ was the frequency of wear power dissipation calculation in one simulation.

\section{Analysis Method on Sensitivity of Diversified Parameters to Wear Power Dissipation of the Wheel}

3.1. Parameter Sensitivity Analysis Method. Sensitivity analysis is a method to analyze the stability of a system. By analyzing the trend and degree of deviation of a system characteristics from the system baseline state caused by the parameters variation of the system, the sensitivity of the system characteristics (referring to the wear power dissipation in this paper) to the system parameters (random factors affecting the wear power dissipation) was determined [36]. The system model was firstly established and the baseline parameters were determined. After that, the sensitivity of the system characteristics to the parameters could be analyzed. When the sensitivity of the system characteristic $P$ to a system parameter $a_{\mathrm{k}}$ was analyzed, the system parameters were changed within its possible range, and base values were taken for the other parameters and remained fixed. In this case, the system characteristics are

$$
P=f\left(a_{1}{ }^{*}, \cdots, a_{k-1}{ }^{*}, a_{k}{ }^{*}, a_{k+1}{ }^{*}, \cdots, a_{n}{ }^{*}\right)
$$

wherein $f$ is system function; $a_{1}{ }^{*}, \ldots, a_{k-1}{ }^{*}, a_{k}, a_{k+1}{ }^{*}, \ldots, a_{n}{ }^{*}$ are the parameters during the system reference state.

To quantify the sensitivity of the system characteristics to the influencing parameters, the sensitivity factor is defined in literature [36]:

$$
S\left(a_{k}\right)=\max \left\{\left(\frac{P_{a_{k} \max }-P^{*}}{P^{*}}\right),\left(\frac{P^{*}-P_{a_{k} \min }}{P^{*}}\right)\right\}
$$


TABLE 2: Design variables of vehicle and track parameters.

\begin{tabular}{|c|c|c|c|c|}
\hline Symbol & Parameter property name & Unit & Base value & Value range \\
\hline$\overline{X_{1}}$ & Longitudinal stiffness of tumbler journal box node & $\mathrm{MN} \cdot \mathrm{m}^{-1}$ & 15 & $6 \sim 24$ \\
\hline$X_{2}$ & Lateral stiffness of tumbler journal box node & $\mathrm{MN} \cdot \mathrm{m}^{-1}$ & 8 & $3.2 \sim 12.8$ \\
\hline$X_{3}$ & Longitudinal stiffness of primary suspension & $\mathrm{MN} \cdot \mathrm{m}^{-1}$ & 0.9 & $0.36 \sim 1.44$ \\
\hline$X_{4}$ & Lateral stiffness of primary suspension & $\mathrm{MN} \cdot \mathrm{m}^{-1}$ & 0.9 & $0.36 \sim 1.44$ \\
\hline$X_{5}$ & Vertical stiffness of primary suspension & $\mathrm{MN} \cdot \mathrm{m}^{-1}$ & 1.5 & $0.6 \sim 2.4$ \\
\hline$X_{6}$ & Longitudinal stiffness of air-spring suspension & $\mathrm{MN} \cdot \mathrm{m}^{-1}$ & 0.15 & $0.12 \sim 0.3$ \\
\hline$X_{7}$ & Lateral stiffness of air-spring suspension & $\mathrm{MN} \cdot \mathrm{m}^{-1}$ & 0.15 & $0.12 \sim 0.3$ \\
\hline$X_{8}$ & Vertical stiffness of air-spring suspension & $\mathrm{MN} \cdot \mathrm{m}^{-1}$ & 0.18 & $0.09 \sim 0.27$ \\
\hline$X_{9}$ & Vertical damping of primary suspension & $\mathrm{kN} \cdot \mathrm{s} \cdot \mathrm{m}^{-1}$ & 50 & $20 \sim 80$ \\
\hline$X_{10}$ & Damping of anti-hunting motion dampers & $\mathrm{MN} \cdot \mathrm{m} \cdot \mathrm{s}^{-1}$ & 0.75 & $0.3 \sim 1.2$ \\
\hline$X_{11}$ & Lateral stiffness of track & $\mathrm{MN} \cdot \mathrm{m}^{-1}$ & 20 & $8 \sim 32$ \\
\hline$X_{12}$ & Vertical stiffness of track & $\mathrm{MN} \cdot \mathrm{m}^{-1}$ & 75 & $30 \sim 120$ \\
\hline$X_{13}$ & Lateral damping of track & $\mathrm{MN} \cdot \mathrm{m}^{-1}$ & 49 & 19.6 78.4 \\
\hline$X_{14}$ & Vertical damping of track & $\mathrm{MN} \cdot \mathrm{m}^{-1}$ & 94 & $37.6 \sim 150.4$ \\
\hline
\end{tabular}

wherein $S\left(a_{k}\right)$ is the parameter sensitivity factor; $P^{*}$ is the system characteristics corresponding to the reference parameter set; and $P_{a_{k} \max }$ and $P_{a_{k} \text { min }}$ were the maximum and minimum values of the system characteristics in the variation range of system parameter $a_{k}$. The sensitivity factor $S\left(a_{k}\right)$ is greater, representing that the system characteristic $P$ is more sensitive to the system parameter $a_{\mathrm{k}}$.

3.2. The Results of Parameter Sensitivity. The base value and value range of each parameter could be reasonably determined through the statistical analysis of track parameters and vehicle parameters of high-speed train in the existing literature [37-42], which are as shown in Table 2.

According to the parameters influencing the wear power dissipation, the influence of separate variation of each parameter on the cumulative wear power dissipation was considered. Every parameter included seven levels' value in its variation range based on a fixed step length, and the rest of the parameters are based on their base values and kept them unchanged. Figures 3 and 4 show the influence of separate variation of each parameter of the vehicle and track on the maximum cumulative wear power dissipation.

It could be seen from Figures 3 and 4 that, in the vehicle parameters, the maximum cumulative wear power dissipation decreases with the increase of the value of damping of antihunting motion damper and the decreased magnitude of the maximum cumulative wear power dissipation value is the largest, with a variation range of $105-305 \mathrm{kN} \bullet \mathrm{m} \bullet \mathrm{s}^{-1}$, and the corresponding maximum cumulative wear power dissipation values of the other parameters are in the range of $110-140 \mathrm{kN}$. $\mathrm{m} \cdot \mathrm{s}^{-1}$, with a small variation range. In the track parameters, the maximum cumulative wear power dissipation decreases with the increase of the vertical damping value of the rail, with the maximum variation range of $116-152 \mathrm{kN} \cdot \mathrm{m} \cdot \mathrm{s}^{-1}$, and the corresponding maximum cumulative wear power dissipation values of the other parameters are in the range of 10-140 $\mathrm{kN} \cdot \mathrm{m} \cdot \mathrm{s}^{-1}$.

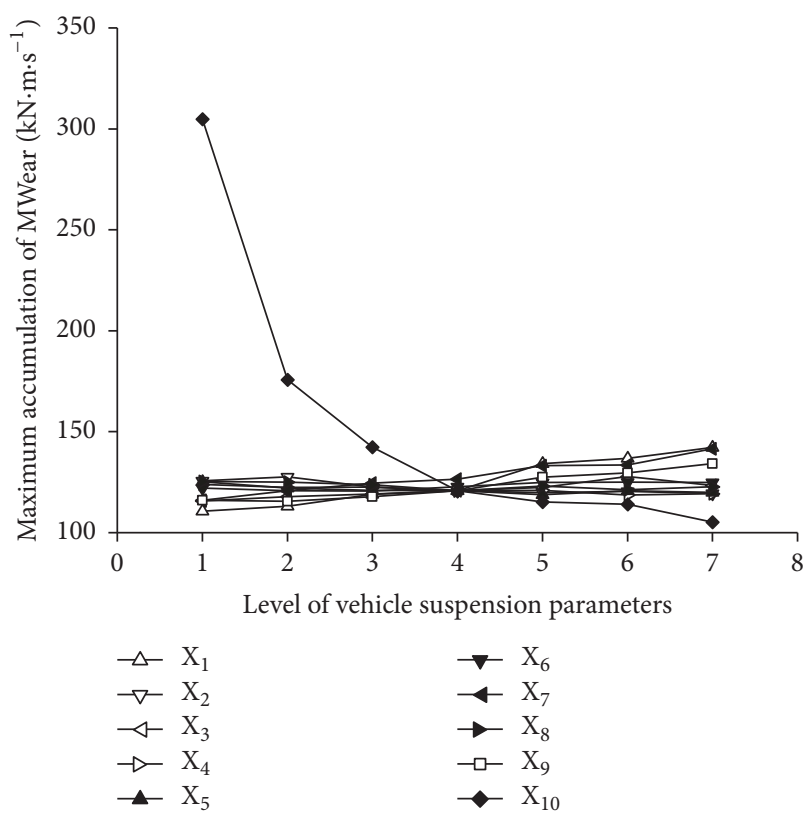

FIGURE 3: Influence of vehicle parameters on the maximum wear power dissipation.

The sensitivity factor is defined according to (4), and the sensitivity factors of the random parameters which influence the maximum cumulative wear power dissipation are defined in Table 3.

Table 3 shows that the cumulative wear power dissipation was the most sensitive to the damping of antihunting motion dampers, followed by the vertical stiffness of tumbler journal box node, lateral stiffness of air-spring suspension, the vertical damping of the second system, vertical stiffness of track, and vertical damping of track, and other parameters are relatively insensitive. 
TABLE 3: Corresponding sensitivity factor of each factor.

\begin{tabular}{|c|c|c|c|}
\hline Parameter property name & Unit & Sensitivity factor & Corresponding parameter value \\
\hline Longitudinal stiffness of tumbler journal box node & $\mathrm{MN} \cdot \mathrm{m}^{-1}$ & 0.178 & 24 \\
\hline Lateral stiffness of tumbler journal box node & $\mathrm{MN} \cdot \mathrm{m}^{-1}$ & 0.057 & 4.8 \\
\hline Longitudinal stiffness of primary suspension & $\mathrm{MN} \cdot \mathrm{m}^{-1}$ & 0.059 & 1.26 \\
\hline Lateral stiffness of primary suspension & $\mathrm{MN} \cdot \mathrm{m}^{-1}$ & 0.026 & 0.36 \\
\hline Vertical stiffness of primary suspension & $\mathrm{MN} \cdot \mathrm{m}^{-1}$ & 0.036 & 0.6 \\
\hline Longitudinal stiffness of air-spring suspension & $\mathrm{MN} \cdot \mathrm{m}^{-1}$ & 0.035 & 0.3 \\
\hline Lateral stiffness of air-spring suspension & $\mathrm{MN} \cdot \mathrm{m}^{-1}$ & 0.173 & 0.3 \\
\hline Vertical stiffness of air-spring suspension & $\mathrm{MN} \cdot \mathrm{m}^{-1}$ & 0.039 & 0.09 \\
\hline Lateral damping of secondary suspension & $\mathrm{kN} \cdot \mathrm{s} \cdot \mathrm{m}^{-1}$ & 0.111 & 80 \\
\hline Damping of anti-hunting motion dampers & $\mathrm{MN} \cdot \mathrm{m} \cdot \mathrm{s}^{-1}$ & 1.524 & 0.3 \\
\hline Lateral stiffness of track & $\mathrm{MN} \cdot \mathrm{m}^{-1}$ & 0.031 & 16 \\
\hline Vertical stiffness of track & $\mathrm{MN} \cdot \mathrm{m}^{-1}$ & 0.123 & 120 \\
\hline Lateral damping of track & $\mathrm{MN} \cdot \mathrm{m} \cdot \mathrm{s}^{-1}$ & 0.003 & 19.6 \\
\hline Vertical damping of track & $\mathrm{MN} \cdot \mathrm{m} \cdot \mathrm{s}^{-1}$ & 0.263 & 37.6 \\
\hline
\end{tabular}

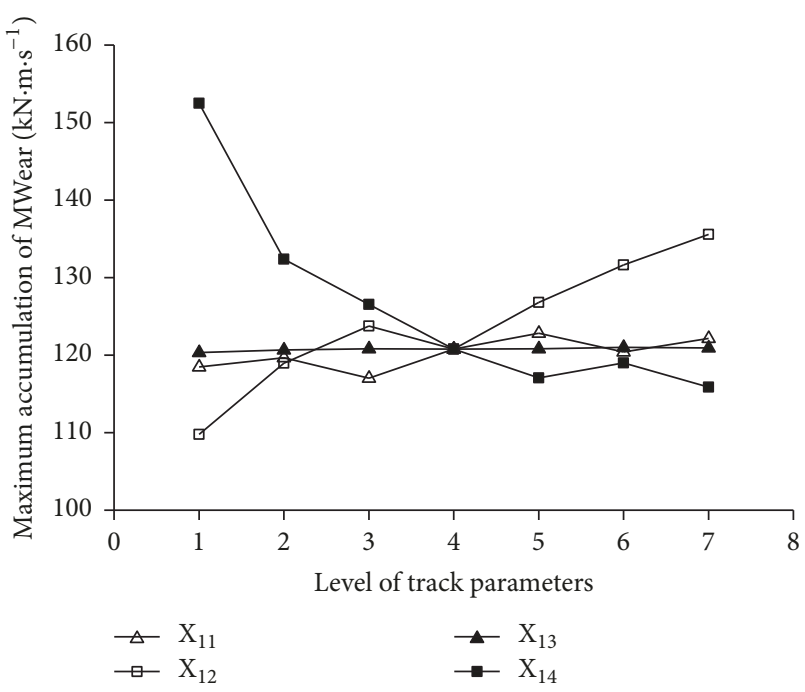

FIGURE 4: Influence of track parameters on the maximum wear power dissipation.

\section{Analysis on Influence of Sensitive Parameters and the Different Wheel-Rail Matching Parameters on the Wheel Hollow Wear}

4.1. Influence of Sensitive Parameters on Wheel Hollow Wear. Based on the above sensitivity analysis results, six sensitivity parameters were determined. Six sensitive parameters such as the damping of antihunting motion damper and longitudinal stiffness of tumbler journal box node were selected to study the influence of them on the wheel hollow wear. The separate variation of each parameter is considered, and the influence of the parameters on the cumulative wear power dissipation at different positions of the wheel during the corresponding value (the value is called the sensitive value) and base value of the sensitivity factor is studied. As shown in Figures 5-10, the origin of the lateral coordinates corresponds to the position

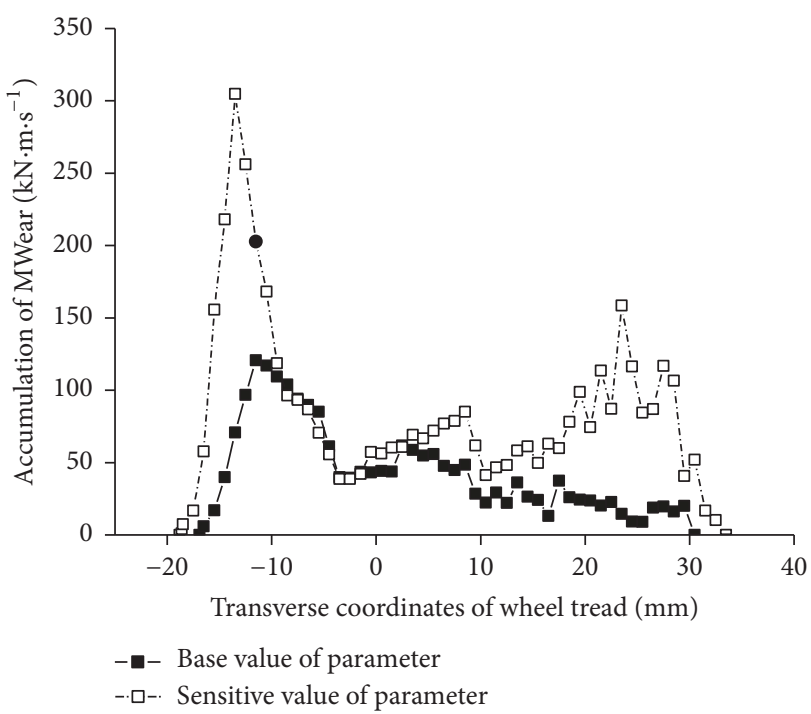

FIGURE 5: Influence of the coefficient of damping of antihunting motion damper on the cumulative wear power dissipation of the wheel.

of the nominal rolling circle of the wheel, and the positive direction pointed to the rim side and the negative direction is away from the rim side.

As could be seen from Figures 5-10,

(1) whether the base value or sensitive value is taken for damping of antihunting motion dampers, longitudinal stiffness of tumbler journal box node, lateral stiffness of air-spring suspension, vertical damping of secondary suspension, vertical stiffness of track, and vertical damping of track, the cumulative wear power dissipation is unevenly distributed in the lateral direction of the wheel tread. It is indicated that the wheel hollow wear is unavoidable in the presence of wheel and rail tread, which is consistent with the field observations $[1,18]$. From the peak features in 


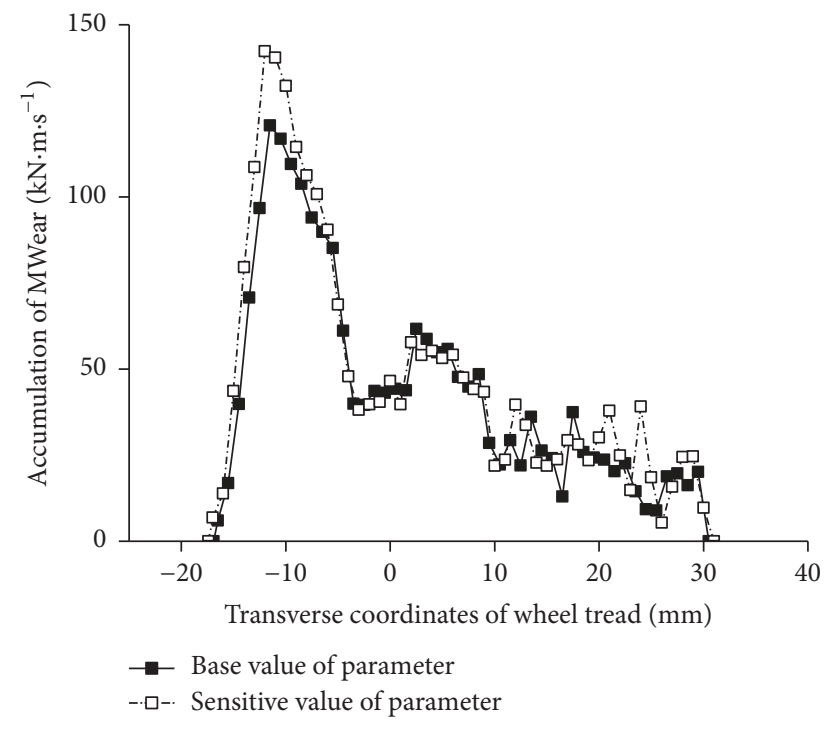

FIGURE 6: Influence of the vertical stiffness of tumbler journal box node on the cumulative wear power dissipation of the wheel.

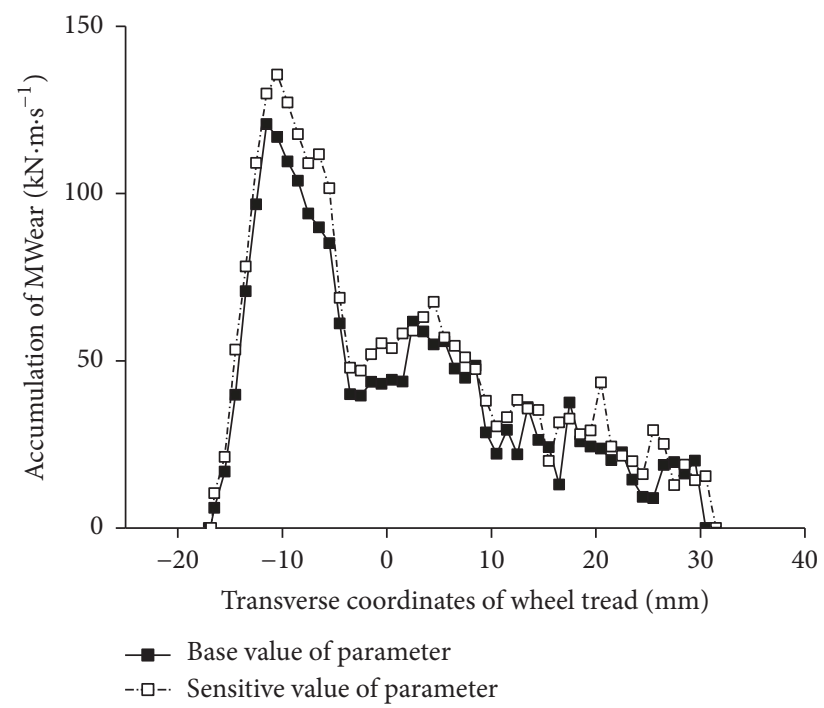

FIGURE 7: Influence of vertical stiffness of the track on the cumulative wear power dissipation of the wheel.

Figures 6-11, there is a significant peak at the position of lateral coordinate of $-10 \mathrm{~mm}$ of the wheel tread, which is basically the same as the position of the maximum point of the hollow wear measured on the filed $[2,3]$.

(2) When the sensitive values are taken for these parameters, the cumulative wear power dissipation of peak point is at least $10 \%$ larger than the cumulative wear power dissipation when the base value is taken. In the case of the sensitive value taken for the coefficient of the damping of antihunting motion dampers, the peak value of the cumulative wear power dissipation is more than two times that at the base value. From the point of view of the nonuniformity of lateral

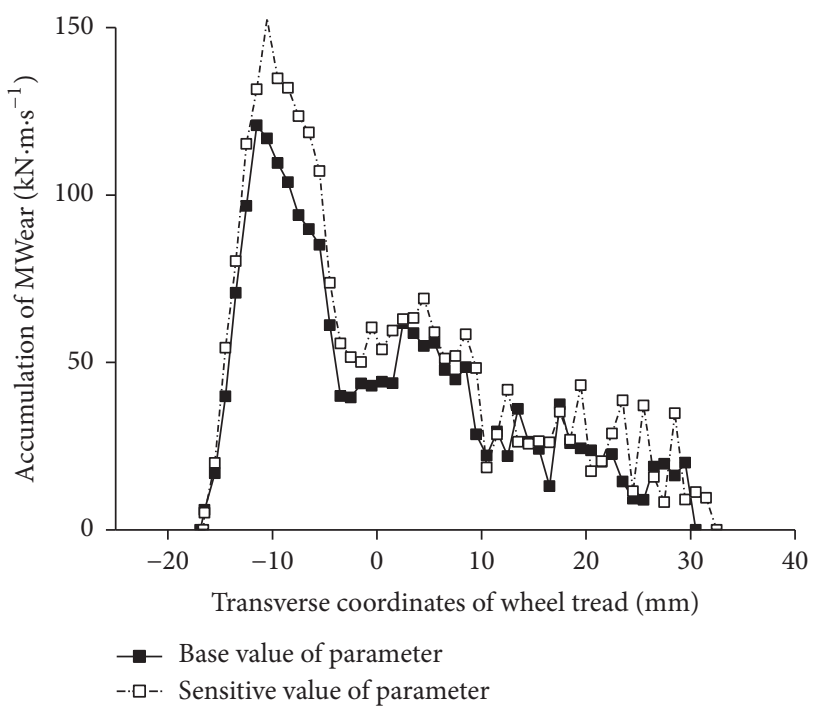

FIGURE 8: Influence of vertical damping of the track on the cumulative wear power dissipation of the wheel.

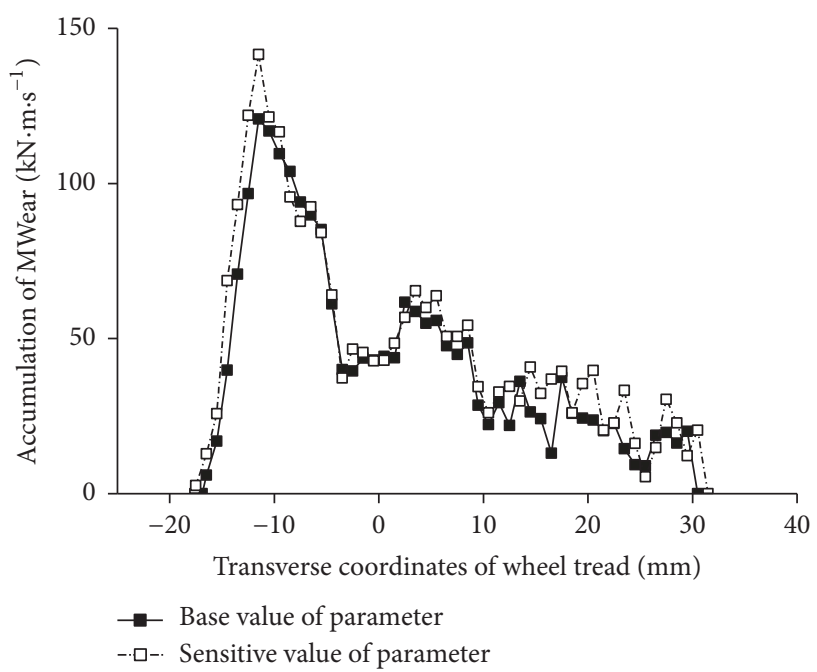

FIGURE 9: Influence of lateral stiffness of the air spring on the cumulative wear power dissipation of the wheel.

cumulative wear power dissipation of the wheel tread, the cumulative wear power dissipation in the range of wheel tread coordinates of $-15.5 \sim-9.5 \mathrm{~mm}$ when the sensitive value is taken for the coefficient of damping of antihunting motion damper reaches $1424 \mathrm{kN} \cdot \mathrm{m}$. $\mathrm{s}^{-1}$, which is 2 to 3 times the cumulative wear power dissipation in the range of the same other contact widths. Therefore, the nonuniformity of lateral distribution of cumulative wear power dissipation of the wheel tread may be reduced through parameter optimization, and the wheel hollow wear may be slowed down.

4.2. Influence of Different Rail and Wheel Tread Matching on the Wheel Hollow Wear. Wheel tread and rail profile 


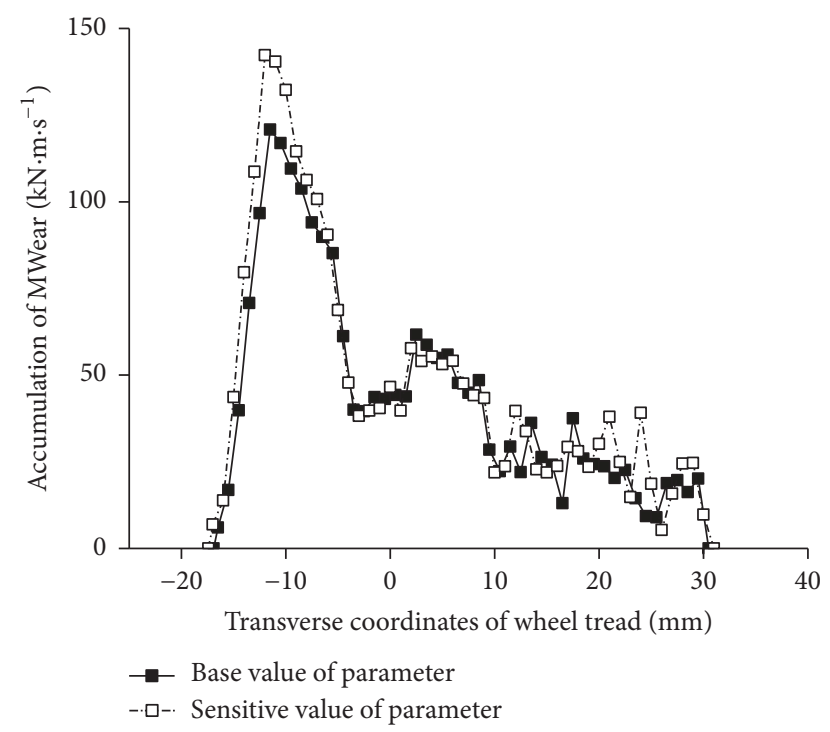

FIGURE 10: Influence of vertical damping of secondary suspension on the cumulative wear power dissipation of the wheel.

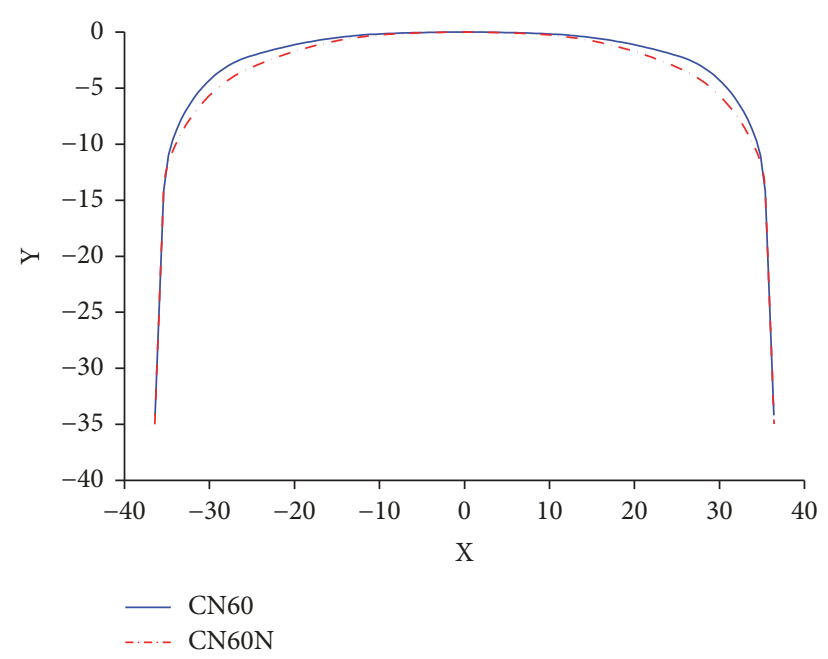

FIGURE 11: Rail tread (unit: $\mathrm{mm}$ ).

are important parameters in wheel-rail contact relationship. Wheel treads of the China's high-speed train are mainly LMA and S1002CN treads; rail is mainly CN60 tread. In order to improve the dynamic performance of the vehicle, especially to make the wheel-rail contact with the appropriate equivalent taper to reduce frame lateral instability of the train and extend the wheel reprofiling and rail grinding cycle, a new rail tread, CN60N tread, was developed [43]. In this paper, the lateral distribution law of wheel wear was analyzed (analyzed under the base values of vehicle and track parameters) by comparison when the wheel treads of S1002CN, LMA, and the worn LMA matched the CN60 and $\mathrm{CN} 60 \mathrm{~N}$ rail treads. The wheel and rail treads used herein are shown in Figures 11 and 12.

Figure 13 shows the cumulative wear power dissipation in the case that the LMA wheel tread matches the different rail

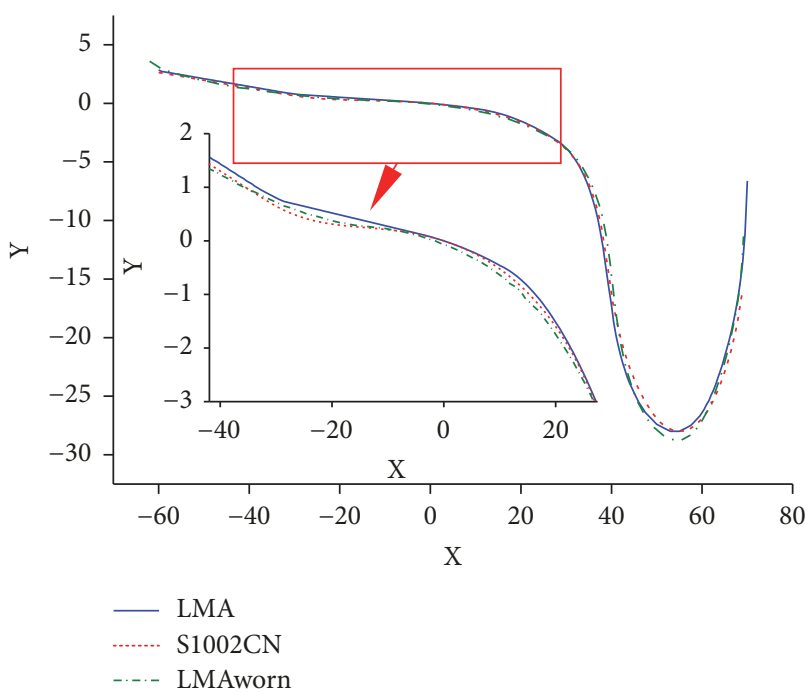

FIGURE 12: Wheel tread (unit: $\mathrm{mm}$ ).

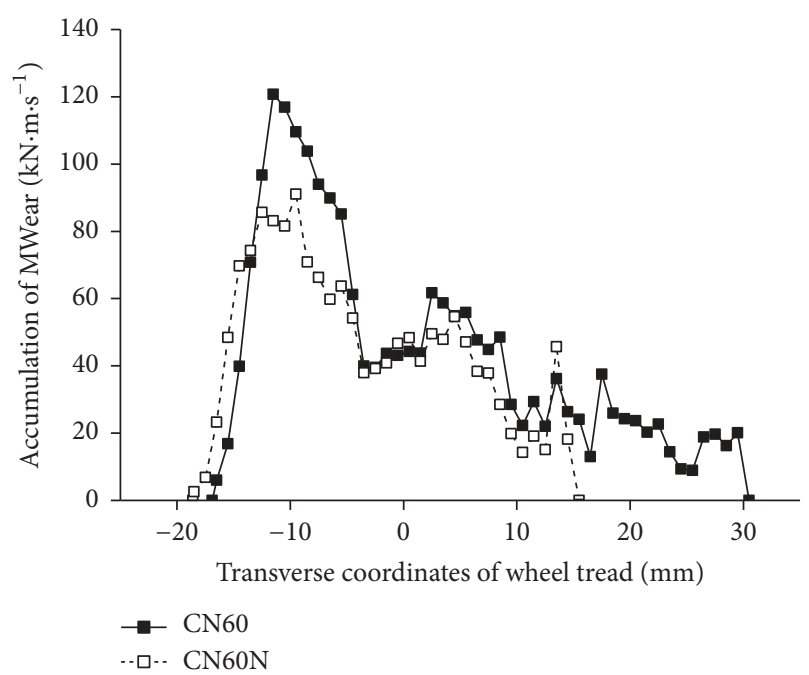

FIGURE 13: Cumulative wear power dissipation (LMA tread matched with the different rail treads).

treads, and the wheel wear range is about $15 \mathrm{~mm}$ smaller than that in the case that the LMA wheel tread matches the CN60 rail tread. From the point of view of the cumulative wear power dissipation at different positions of lateral direction of the wheel, the cumulative wear power dissipation at different positions in the case that the LMA wheel matched the CN60N rail tread is smaller than that in the case that the LMA wheel matches the $\mathrm{CN} 60$ rail tread, from the region with a relatively large wear power dissipation of the wheel, when the LMA wheel tread matches with the $\mathrm{CN} 60, \mathrm{CN} 60 \mathrm{~N}$ rail treads, and it is mainly concentrated in the range of the wheel tread coordinates of -12.5 -7.5mm; when the LMA wheel tread matches the CN60 rail tread, the cumulative wear power dissipation in this range is $641 \mathrm{kN} \cdot \mathrm{m} \cdot \mathrm{s}^{-1}, 2-3$ times the cumulative wear power dissipation in the range of the other same widths; when matching the $\mathrm{CN} 60 \mathrm{~N}$ rail, the cumulative wear power dissipation in the range of the same widths is 478 


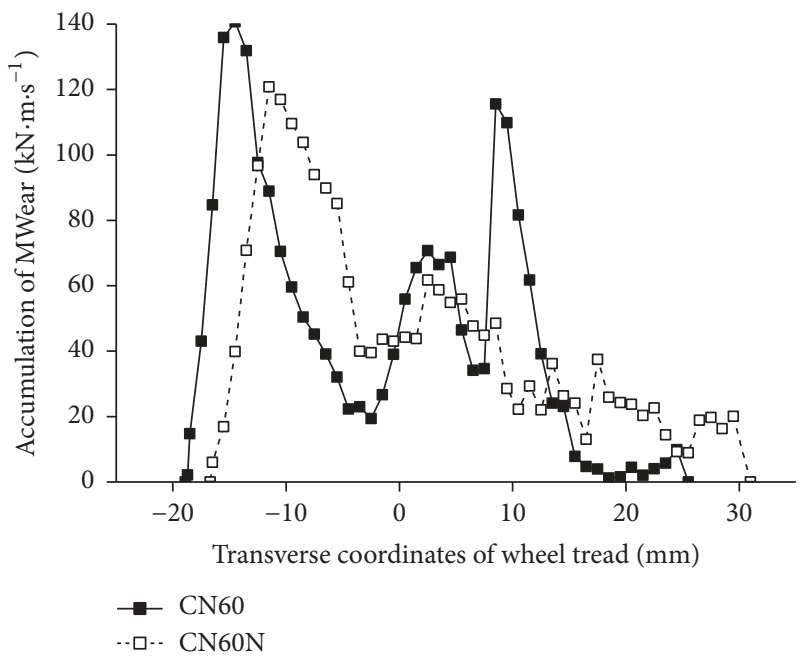

FIGURE 14: Cumulative wear power dissipation (S1002CN tread matched with the different rail treads).

$\mathrm{kN} \cdot \mathrm{m} \cdot \mathrm{s}^{-1}$, more than 1 time the cumulative wear power dissipation in the range of the other same widths. Therefore, when the LMA wheel tread is matched with the $\mathrm{CN} 60 \mathrm{~N}$ rail tread, it could not only reduce the wheel hollow wear but also reduce the wheel wear rate.

Figure 14 shows the cumulative wear power dissipation when the S1002CN wheel tread matched the different rail treads. From the point of view of the range of wear distribution, when the $\$ 1002 \mathrm{CN}$ wheel tread matches the CN60, $\mathrm{CN} 60 \mathrm{~N}$ rail treads, the wheel wear range is basically the same, but when it matches the $\mathrm{CN} 60 \mathrm{~N}$ rail tread, the area where the wheel wear is produced moved about $5 \mathrm{~mm}$ toward the direction of the rim, from the point of view of the cumulative wear power dissipation at different positions in the lateral position of the wheel, and the cumulative wear power dissipation ratio at different positions when the $\mathrm{S} 1002 \mathrm{CN}$ wheel tread matches the $\mathrm{CN} 60 \mathrm{~N}$ rail tread is different from the cumulative wear power dissipation when it matches with the $\mathrm{CN} 60$ rail tread. The maximum value of the cumulative wear power dissipation when the $\mathrm{S} 1002 \mathrm{CN}$ wheel tread matches the $\mathrm{CN} 60 \mathrm{~N}$ tread is smaller than that when the $\mathrm{S} 1002 \mathrm{CN}$ wheel tread matches the $\mathrm{CN} 60$ rail tread. From the point of view of relatively large wear power dissipation of the wheel, when the S1002CN wheel tread matches the different rail treads, the difference of the peak area of the wear power dissipation is relatively large. When the S1002CN wheel tread matches the $\mathrm{CN} 60$ rail tread, the three places with the relatively large peak values of the cumulative wear power dissipation of the wheel appeared, which are at $-16.5-11.5 \mathrm{~mm}$, $2.5-7.5 \mathrm{~mm}$ and $7.5-12.5 \mathrm{~mm}(2.5-7.5 \mathrm{~mm}$ in which the peak is relatively small); in the wheel tread range of $-16.5 \sim-11.5 \mathrm{~mm}$, the cumulative wear power dissipation is $680 \mathrm{kN} \cdot \mathrm{m} \cdot \mathrm{s}^{-1}$, 2-5 times within the same width of the nonpeak area of the other wear power dissipation. In the range of wheel tread 7.5$12.5 \mathrm{~mm}$, the cumulative wear power dissipation is $442 \mathrm{kN} \cdot \mathrm{m}$. $\mathrm{s}^{-1}, 1.5-3$ times within the nonconcentrated wear area of the other same widths; when the $\mathrm{S} 1002 \mathrm{CN}$ wheel tread matches the $\mathrm{CN} 60 \mathrm{~N}$ rail tread, there are two positions with the large peak value for the cumulative wear power dissipation of the wheel, which is mainly in the wheel tread $-12.5 \sim-7.5 \mathrm{~mm}$ and 2.5-7.5mm (where the peak position matches the S1002CN wheel tread and $\mathrm{CN} 60 \mathrm{~N}$ rail tread, the position of the smaller peak value point of the cumulative wear power dissipation is basically the same), and, in the range of the wheel tread coordinates of $-12.5 \sim-7.5 \mathrm{~mm}$ range, the cumulative wear power dissipation is $641 \mathrm{kN} \cdot \mathrm{m} \cdot \mathrm{s}^{-1}, 2-4$ times the same cumulative wear power dissipation in the range of the other same widths.

The following could be concluded from Figures 13 and 14:

(1) Under the same line conditions, and when the different wheel treads match the rail treads, the wheel wear and its distribution are quite different. Although the sensitivity factor could not be calculated under matching conditions of different wheel and track treads, the maximum cumulative wear power dissipation fluctuation of wheel is more than $15 \%$ in the case of different wheel-rail treads matching. The cumulative wear power dissipation of the wheel tread is laterally distributed during different wheelrail treads matching; i.e., the lateral distribution of wear also changes. Therefore, the wheel and rail treads are also the sensitive parameters of the wheel hollow wear.

(2) Whether from the point of view of peak value of the cumulative wear power dissipation or from the point of view of nonuniformity of the traversal distribution, the LMA tread wheel matching with the CN60, $\mathrm{CN} 60 \mathrm{~N}$ rail treads is better than the $\mathrm{S} 1002 \mathrm{CN}$ tread wheel matching with the $\mathrm{CN} 60$, $\mathrm{CN} 60 \mathrm{~N}$ treads; from analysis of the hollow wear and wear rate, the LMA tread wheel matching the $\mathrm{CN} 60 \mathrm{~N}$ tread rail is the best pair of these four kinds of matching.

Wheel wear occurs in the course of its use, resulting in variation of the wheel tread, which also leads to variation of contact relation between the wheel and rail, causing the changes in the wheel wear distribution law. In this paper, the actual measured wheel tread after the wear was taken as the object to compare and analyze the lateral distribution law of the wheel wear when the wheel tread LMA worn was matched with two kinds of rail treads, which is as shown in Figure 15.

From Figure 15, when the worn wheel tread matches the two rail treads, a very large peak value of the cumulative wear power dissipation is appeared, and the cumulative wear power dissipation that matches $\mathrm{CN} 60$ and $\mathrm{CN} 60 \mathrm{~N}$ reaches $3477 \mathrm{kN} \cdot \mathrm{m} \cdot \mathrm{s}^{-1}$ and $5058 \mathrm{kN} \cdot \mathrm{m} \cdot \mathrm{s}^{-1}$, respectively, in the range of $-6.5 \sim-5.5$ and $-2 \sim-11 \mathrm{~mm}$, which is 10 to 100 times in the range of $1 \mathrm{~mm}$ in other positions. Compared with Figure 13, the accumulated wear power dissipation of the worn LMA wheel tread is bigger than that of the new LMA tread when it matches the $\mathrm{CN} 60$ and $\mathrm{CN} 60 \mathrm{~N}$ rail treads, and the wheel reprofiling shall be timely carried out. Field observations found that the wear rate of the worn wheel is relatively large, while the wear rate of the wheel is reduced 


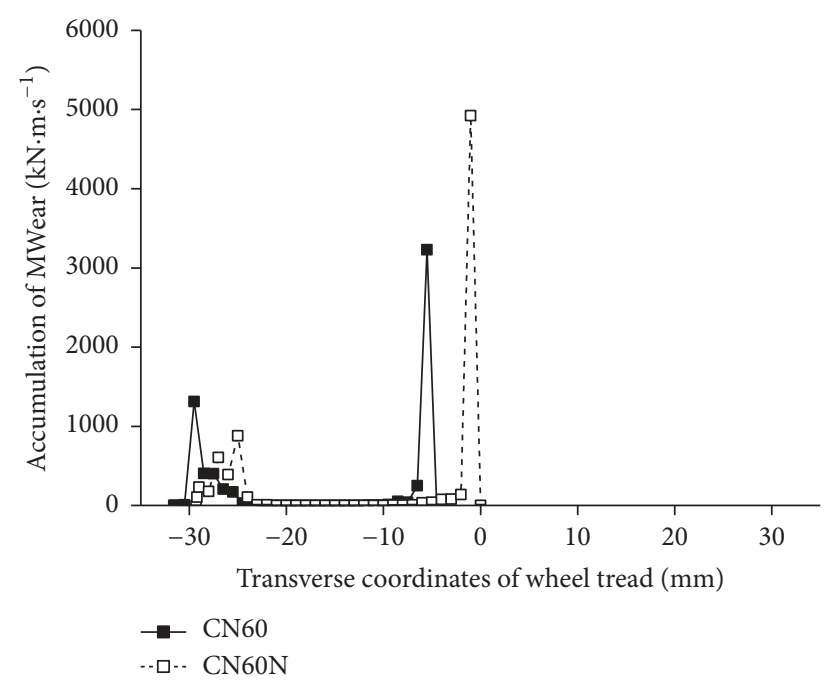

FIgURE 15: Cumulative wear power dissipation (LMAworn wheel tread matched with the different rail treads).

after the wheel reprofiling [2]. The simulation results in this paper are consistent with those observed in the field.

\section{Conclusion}

(1) The simulation results show that the maximum cumulative wear power dissipation is the most sensitive to the damping of antihunting motion dampers, followed by longitudinal stiffness of tumbler journal box node, lateral stiffness of air-spring suspension, vertical damping of secondary suspension, vertical stiffness of track, and vertical damping of track, and the other parameters are relatively insensitive. From the point of view of the parameter sensitivity, it is possible to reduce the wheel hollow wear by optimizing the vehicle suspension parameters.

(2) In the case that the LMA wheel tread matches the CN60 rail tread, the cumulative wear power dissipation is unevenly distributed along the lateral direction of the wheel tread under the influence of various vehicle and track parameters, and it is inevitable that the wheel is sagged due to wear.

(3) When the different rail treads match the wheel treads, there is a great difference for the wheel wear law. The matching between the LMA wheel tread and the $\mathrm{CN} 60 \mathrm{~N}$ rail tread is a good match, either from slowing the hollow wear or from slowing down the wheel wear rate, but the wheel reprofiling shall be timely carried out; otherwise the wear rate will increase, and hollow wear becomes more serious.

It is concluded that the parameter optimization could reduce the wheel hollow wear through the parameter sensitivity analysis but could not avoid the hollow wear. How to reduce the wheel hollow wear through the parameter optimization is a multiobjective optimization problem, and not only the is wheel hollow wear needed, but also the issues such as the vehicle driving safety and economy of reprofiling should be considered, which is a subject worthy of study.

\section{Data Availability}

The data used to support the findings of this study are available from the corresponding author upon request.

\section{Conflicts of Interest}

The authors declare that they have no conflicts of interest.

\section{Acknowledgments}

This work was supported by National Natural Science Foundation of China (no. 11572207, no. 51208319), Hebei Provincial Natural Science Foundation of China (no. A2016210103, no. E2015210099, and no. E2016210131), and Key Project of Hebei Educational Committee of China (no. ZD2015037).

\section{Supplementary Materials}

The supplementary material is a graphical abstract. The graphical abstract is a single, concise, pictorial, and visual summary of the main findings of the article. (Supplementary Materials)

\section{References}

[1] Z.-W. Huang, D.-B. Cui, X. Du, and X.-S. Jin, "Influence of deviated wear of wheel on performance of high-speed train running on straight tracks," Tiedao Xuebao/Journal of the China Railway Society, vol. 35, no. 2, pp. 14-20, 2013.

[2] X.-J. Zhang, D.-L. Yu, X.-W. Song et al., "Measurement of wheel tread wear of EMU," Railway Innovation, vol. 4, pp. 27-30, 2014.

[3] H. Peng and W.-H. Zhang, "Prediction model and verification of wheel wear in high-speed trains," Jixie Gongcheng Xuebao/Journal of Mechanical Engineering, vol. 52, no. 2, pp. 144149, 2016.

[4] R. Fröhling, A. Ekberg, and E. Kabo, "The detrimental effects of hollow wear-field experiences and numerical simulations," Wear, vol. 265, no. 9-10, pp. 1283-1291, 2008.

[5] K. Sawley, C. Urban, and R. Walker, "The effect of hollow-worn wheels on vehicle stability in straight track," Wear, vol. 258, no. 7-8, pp. 1100-1108, 2005.

[6] K. Sawley and H. Wu, "The formation of hollow-worn wheels and their effect on wheel/rail interaction," Wear, vol. 258, no. 7-8, pp. 1179-1186, 2005.

[7] K. Sawley, Wheel/rail profile maintenance, World Congress on Railway Research (WCRR), Köln, Germany, 2001.

[8] K. Sawley, "Harmful concave worn wheel tread needing turning," Foreign Rolling Stock, vol. 37, no. 3, pp. 44-46, 2000.

[9] H.-L. Li, F. Li, and Y.-H. Huang, "Research on wheel hollow wear and dynamic performance of freight radial bogies," Proceedings of the Institution of Mechanical Engineers, Part F: Journal of Rail and Rapid Transit, vol. 231, no. 9, pp. 1015-1021, 2017.

[10] S. E. Mace, R. Pena, N. G. Wilson, and D. DiBrito, "Effects of wheel-rail contact geometry on wheel set steering forces," Wear, vol. 191, no. 1-2, pp. 204-209, 1996. 
[11] H.-M. Wu and B. Kerchof, "Management of wheel/rail interface to prevent rail rollover derailments," Proceedings of the Institution of Mechanical Engineers, Part F: Journal of Rail and Rapid Transit, vol. 228, no. 6, pp. 673-686, 2014.

[12] H. Tavakkoli, R. Ghajar, and J. Alizadeh K., "The influence of tread hollowing of the railway wheels on the hunting of a coach," in Proceedings of the ASME 2010 International Mechanical Engineering Congress and Exposition, IMECE 2010, pp. 895-900, can, November 2010.

[13] J. Alizadeh Kaklar, R. Ghajar, and H. Tavakkoli, "Modelling of nonlinear hunting instability for a high-speed railway vehicle equipped by hollow worn wheels," in Proceedings of the Institution of Mechanical Engineers, Part K: Journal of Multi-body dynamic, vol. 230, pp. 553-567, 2016.

[14] M. Woolley, Possible re-design of P8 wheel profiles, London,rail safety and standards board, 2002.

[15] X.-L. Li, W.-H. Ma, and S.-H. Luo, "Effect of tread wear on subway vehicle dynamic performance," Locomotive, vol. 1, pp. 17-20, 2013.

[16] Y. Sun, S.-Y. Zhu, and W.-M. Zhai, "Influence of tread hollowworn wheel on wheel/rail interaction," Journal of Mechanical Engineering, vol. 54, no. 4, pp. 109-116, 2018.

[17] B. Kerchof, Interaction of tread-hollow wheel and worn switch point / stock rail, American Railway Engineering and Maintenance-of-Way Association, Nashville, TN, USA, 2004.

[18] X.-S. Jin, G.-T. Zhao, S.-L. Liang, G.-Q. Tao et al., "Characteristics, Mechanisms, Influences and Counter Measures of High Speed Wheel/Rail Wear: Transverse Wear of Wheel Tread," Journal of Mechanical Engineering, vol. 54, no. 4, pp. 3-13, 2018.

[19] Y. Akihiro, "Railroad vehicle wheel wear tendency and life prediction," Foreign Rolling Stock Technology, vol. 1, pp. 31-32, 2011.

[20] S. Kenji, "The trend of wheel wear and characteristics of vehicle operation in new type commuter electric vehicles," Foreign Rolling Stock, vol. 45, no. 4, pp. 39-44, 2008.

[21] X.-J. Sun and W.-X. Zhou, "Effect of tread wear and its influence on the geometric relationship between wheel-rail contact," Railway Rolling Stock, vol. 48, no. 7, pp. 1-4, 2010.

[22] X. Li, Z.-F. Wen, and X.-S. Jin, "Analysis of abnormal wear on metro wheel tread," Jixie Gongcheng Xuebao/Journal of Mechanical Engineering, vol. 46, no. 16, pp. 60-66, 2010.

[23] F. Qing, "Experimental Study on abnormal wear of wheel tread in metro vehicles," Railway Vehicles, vol. 49, no. 6, pp. 28-32, 2011.

[24] C.-H. Huang, R. Luo, J. Zeng, and C.-Y. Song, "Effect of system parameters on tread-hollow wear of high-speed train wheels," Jiaotong Yunshu Gongcheng Xuebao/Journal of Traffic and Transportation Engineering, vol. 16, no. 3, pp. 55-62, 2016.

[25] K. Karttunen, E. Kabo, and A. Ekberg, "Numerical assessment of the influence of worn wheel thread geometry on rail and wheel deterioration," Wear, vol. 317, no. 1-2, pp. 77-91, 2014.

[26] D.-B. Cui, H.-Y. Wang, L. Li, and X.-S. Jin, "Optimal design of wheel profiles for high-speed trains," Proceedings of the Institution of Mechanical Engineers, Part F: Journal of Rail and Rapid Transit, vol. 229, no. 3, pp. 248-261, 2015.

[27] Y. Li, Stduy on effects of high-speed trains dynamic parameters and their applications, Southwest Jiaotong University, Cheng Du, China, 2013.

[28] J. Zhang, Optimal design research of railway vehicle wheel profile, Southwest Jiaotong University, Cheng Du, China, 2013.
[29] D. Cheng, C.-G. Wang, and J.-C. Liu, "Reseatch progress of multi-objective optimization design of wheel profile," Railway Locomotive and Car, vol. 30, no. 4, pp. 5-11, 2010.

[30] M. Ignesti, A. Innocenti, L. Marini, E. Meli, and A. Rindi, "Development of a wear model for the wheel profile optimisation on railway vehicles," Vehicle System Dynamics, vol. 51, no. 9, pp. 1363-1402, 2013.

[31] M. Ignesti, A. Innocenti, L. Marini, E. Meli, A. Rindi, and P. Toni, "Wheel profile optimization on railway vehicles from the wear viewpoint," International Journal of Non-Linear Mechanics, vol. 53, pp. 41-54, 2013.

[32] State Railway Administration, TB/T 3352-2014 PSD of ballastless track irregularities of high-speed railway, Bei Jing, 2014.

[33] J.-Q. Gong, L.-C. Tan, and T.-F. Yu, Wheel/rail wear, China Railway Press, Beiing, China, 1997.

[34] D. Pogorelov, "Railway wheel and rail profile wear prediction module-User'S Manual," Tech. Rep., Bryansk state technical universitiy, Bryansk, Russia, 2012.

[35] Z.-L. Li, Wheel-rail rolling contact and its application to wear simulation, Delft University of Technology, Delft, Netherlands, 2002.

[36] J.-X. Wang, Y.-D. Xu, and W. Xiao, "Sensitivity analysis of mechanical parameters of rail to fatigue crack initiation Life," Journal of Shijiazhuang Railway Institute (Natural Science), vol. 22, no. 1, pp. 15-18, 2009.

[37] X. Ying and J. Jiang, "Optimization of suspension parameters of high-speed trains based on kriging proxy model," Journal of Lanzhou Jiaotong University, vol. 34, no. 1, pp. 107-108, 2015.

[38] X.-R. Wang, "Discussion on sensitivity and coupling relationship of suspension parameters of High Speed Passenger Car Bogies," Railway Locomotive \& Rolling Stock, vol. 2, pp. 13-14, 2000.

[39] C. Maoru, Z. Weihua, Z. Jing et al., "Analysis of suspension parameters of high speed passenger car bogies," Journal of Dalian Jiaotong University, vol. 28, no. 3, pp. 14-18, 2007.

[40] M. Zhang, L. Zhang, Y.-P. Luo et al., "Modeling and analysis of SIMPACK simulation for dynamic performance of bogies on high speed trains," Urban Rail Transit Research, vol. 18, no. 10, pp. 36-41, 2015.

[41] G.-M. Zhang, "Study on evaluation indexes for reasonable value of track stiffness," China Railway Science, vol. 23, no. 1, pp. 51-57, 2002.

[42] H.-Y. Liu and J. Zeng, "Influence of whole stiffness and damping of track on dynamic performance of vehicle," Railway Rolling Stock, vol. 42, no. 4, pp. 1-4, 2004.

[43] Q.-Y. Zhou, Y.-H. Zhang, C.-H. Tian et al., "Profile design and test study of $60 \mathrm{~N}$ rail," Zhongguo Tiedao Kexue/China Railway Science, vol. 35, no. 2, pp. 128-135, 2014. 


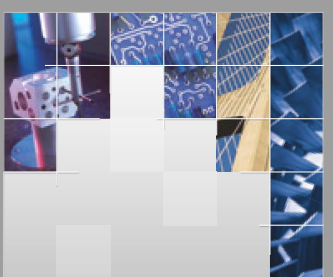

\section{Enfincering}
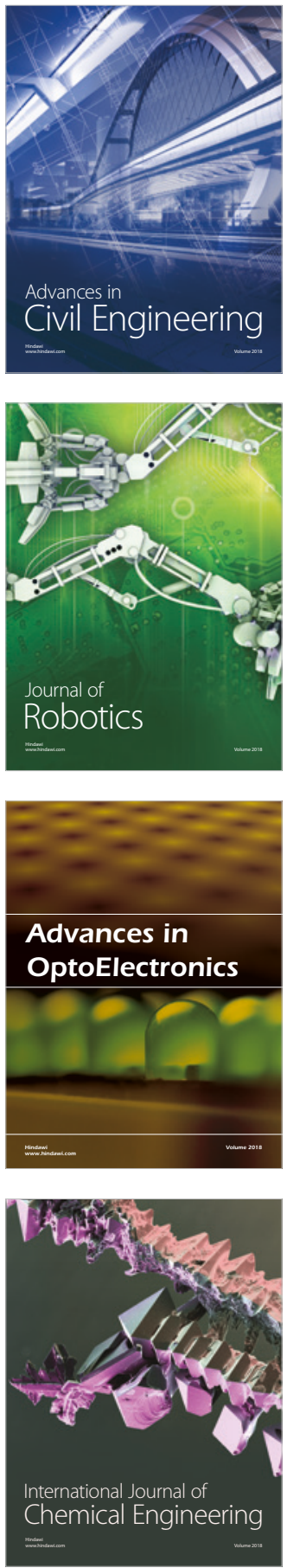

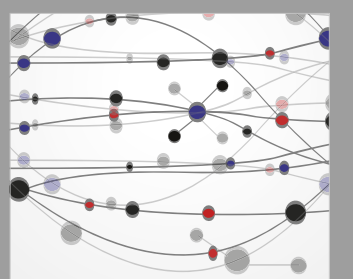

\section{Rotating \\ Machinery}

The Scientific World Journal

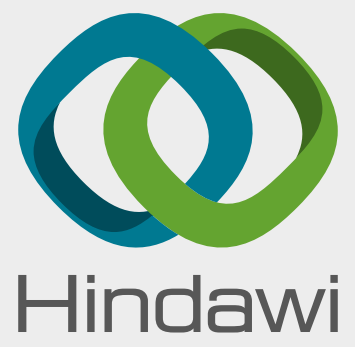

Submit your manuscripts at

www.hindawi.com
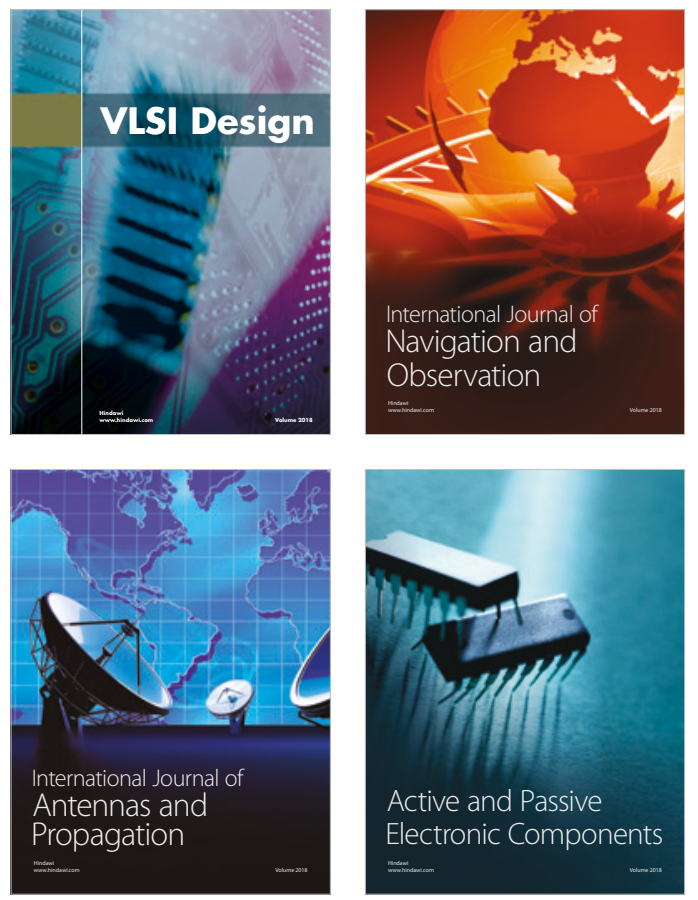
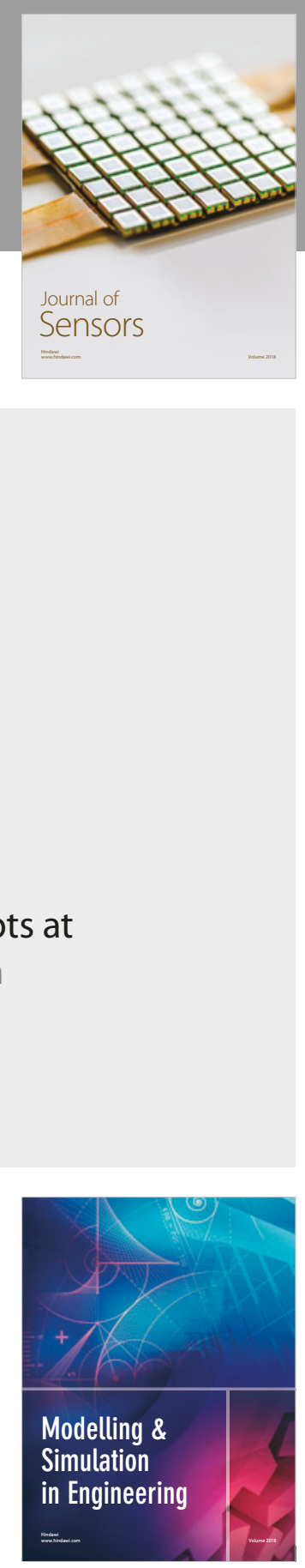

\section{Advances \\ Multimedia}
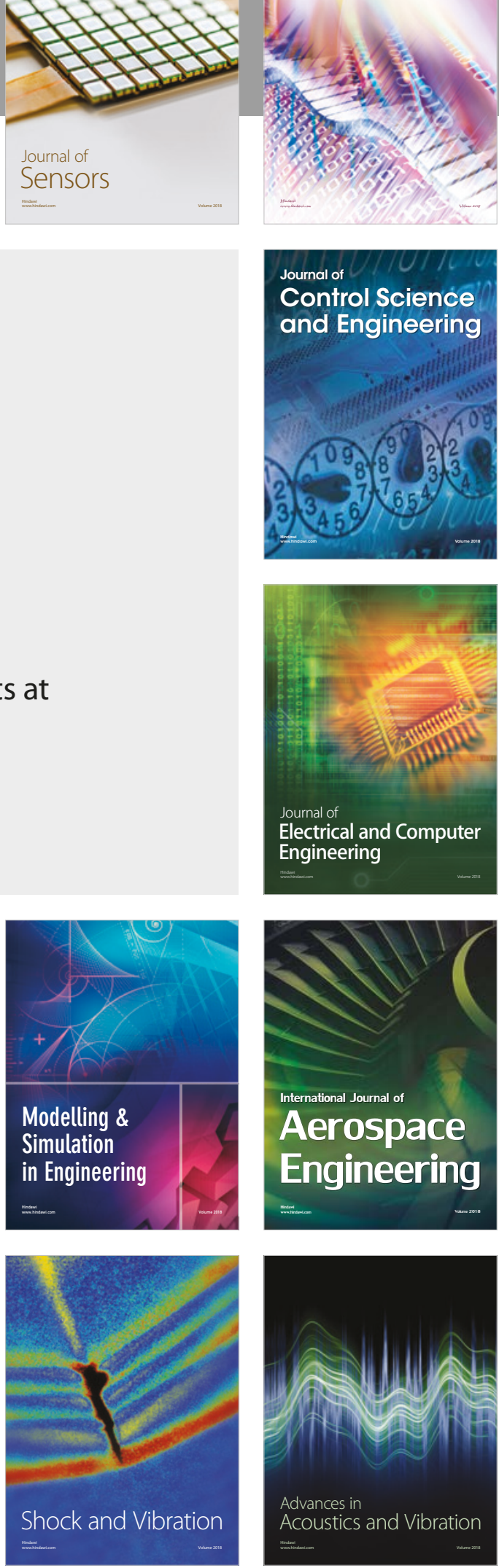